\title{
The Development of an Evidence Based, Evidence Generating Framework for Enhancing Indigenous Student Success at an Australian University
}

\author{
Braden Hill \\ Pro-Vice-Chancellor (Equity and Indigenous) and Head of Centre \\ Francesca Robertson \\ Senior Researcher \\ Grantley Winmar \\ Student Success Officer \\ Tracey Lee \\ Centre Manager \\ Tilly Casey \\ Student Success Officer, \\ Keneasha Lindsay \\ Student Success Officer \\ Kurongkurl Katijtin \\ Centre for Indigenous Australian Education and Research \\ Edith Cowan University, Perth. \\ Dellas Bennell \\ Senior Indigenous Student Support Officer \\ Edith Cowan University, South West Campus, Bunbury
}

\begin{abstract}
In 2019, Kurongkurl Katitjin, Centre for Indigenous Australian Education and Research at Edith Cowan University, set up a new Indigenous student support service with the aim of enabling Indigenous students to progress through their degree at rates commensurate with the broader student population. This was an opportunity to design the service on the best available evidence and to embed an ongoing evaluation system that would generate evidence of its efficacy and with that, the capacity of ongoing refinement. The design of the service synthesised material from four discourses; existing literature on Indigenous student success, the demography of students, and best practice for service provision for marginalised and student voices. Key values and a service mission were identified, these underpinned the process of design, and the operations of the service. A framework was developed that enabled the generation of quantitative and qualitative data about the efficacy of the service. This paper demonstrates the significance of the process of design as well as describing the service and its embedded evaluation system.
\end{abstract}

\section{Key words}

Indigenous, student, retention, success

\section{Introduction}

The number of Indigenous students enrolling at universities has increased modestly in the last decade, up from $1.3 \%$ in 2008 to $1.8 \%$ in 2017 . It remains below population parity of $3.1 \%$ (Universities Australia Indigenous Strategy, First Annual Report, 2017). Bachelor's degree completion rates for Australian and New Zealand Indigenous students has remained poor compared to non-Indigenous students. For example, while Australian Indigenous students typically can take longer to graduate, 9year completion rates for such students remains around $47 \%$, significantly below the $74 \%$ for nonIndigenous students (Higher Education Student Collection, 2019). 
Community outreach, alternative entry pathways, dedicated centres and units of excellence and support programs that respond to the needs of Australian Indigenous students have helped to improve enrolment, retention and completion rates (Universities Indigenous strategy, 2017-2020). In 2017, the Australian Commonwealth government made a new approach to Indigenous student support funding. It enabled greater autonomy in the higher education sector in deciding how support funding could be deployed to ensure Indigenous students are able to readily access university, feel supported throughout their journeys and, ultimately, complete their elected courses of study. While the former funding regime rewarded institutions for their focus on increasing Indigenous access and participation at university, the new Indigenous Student Success Program shifted its focus towards incentivising activities that supported Indigenous students to progress through their degree at rates commensurate with the broader student population.

Kurongkurl Katitjin, Centre for Australian Aboriginal Education and Research at Edith Cowan University expressed its commitment to Indigenous students in an eight pillar Strategic and Operation Plan to enhance Indigenous student success. This plan recognises the need for a better support system for students. The support system was developed in the first half of 2019 and implemented on an experimental basis in the second half of the year with a small newly enrolling cohort and with students seeking assistance from the Centre. This paper describes how the support service, known as the Student Success Service, and its embedded multi-model feedback was developed and gives the results of the trial implementation.

\section{Methodology}

The Student Success Team consists of one pre-existing and three new Success Officers, their manager, all of whom are local Indigenous people, and an advisor with years of practice in service design and delivery. They met regularly to develop the service. This process began with an extensive literature survey covering four areas:

- The higher education Indigenous student success discourse;

- The discourse concerning the efficacy of services targeted to marginalised people;

- Population trends, to establish demographic profiles of Indigenous students in Western Australia from ABS statistics and from Indigenous student statistics from various sources; and

- ECU student voices derived from the annual Aboriginal Student Satisfaction Survey (the Survey) prepared by Kurongkurl Katitjin staff and first applied in Semester 2019. Of the 356 Indigenous students, who were studying at ECU during this time, 175 students had completed the survey by 18 April 2019.

At the same time, Success Officers were responding to students seeking help at the centre based at three campuses, establishing fresh mechanisms for accessing Aboriginal Tutorial and Mentoring Programs (AMPT) and scholarships, and developing systems for communicating with students. Three of the Success Officers, as recently graduated Aboriginal people, also had their own lived experience to call on.

The Success Team used collaborative inquiry methods (Heron, 1996), to develop a shared understanding and language around the service and its potential structure. When collaborative inquiry is used in this context, it typically becomes action research, a praxis intervention method. Action research follows a four-step process of planning, action, observing and reflecting (McNiff, 2013). Also known as co-operative research (Reason and Rowan, 1981), action research explores four different types of knowledge:

- Propositional knowing (that provided by the literature search); 
- Practical knowing (that provided by the advisor and the activities currently undertaken by Success Officers);

- Experiential knowing (application and feedback about application in the experimental phase); and

- Presentational knowing (crafting and articulating new practices). Discussions about the service took on a cycling and recycling process, each time deepening experience and knowledge.

Action research methods were crucial in the overall development of the service. In the first phase the collaborative inquiry method was used again and again to develop shared understanding, language and clarity about various aspects of the service. The Success Team considered how a service could be implemented and how students' responses to the service could be measured. A framework, consisting of two linked matrices, was designed to guide conversations with students and to identify the type and level of support offered. Once the support system was designed it was decided to have an experimental phase with a limited number of students. Feedback from service recipients and deliverers could be used to refine the service before it was applied broadly. This process took a year with design elements taking place in the first six months and an experimental phase in the second six months of 2019. The following year it was implemented across the new intake.

\section{Ethics}

In 2019 the generation of data fell into the quality assurance remit, however, its experimental nature required operational principles, which include signed consent for the use of the framework and follow-up, a genuine assurance of operational values and opt-in, opt-out mechanisms. The Success Team felt there were two ethical questions in the process. Firstly, is there a line between activities that relate to quality assurance or evaluation and activities that relate to research? Secondly, is that line affected by the use of quality assurance data in publications? When no research or publications are intended then the collection of non-identified quantitative data can be understood to be within the sphere of quality assurance and evaluation activities (NHMRC, 2014). If it is intended to use the data for research purposes and publication then the process should have ethics approval (Fahy, 2009). It is intended that Kurongkurl Katitjin will further research any issues that are thrown up by the implementation of the system, and publish academic papers on the findings of service evaluation because there is a dearth of published empirical evidence about what makes an effective student support service. Ethics approval was sought and given.

\section{Findings from the literature}

The literature search in the higher education success discourse was conducted using keywords; Indigenous and university and students and (in turn) support, success, retention and counselling. The aim was to find specific supports that had been found useful in improving the retention rates for students. Very little peer-reviewed research that is primarily concerned with the specifics of 'what works' in terms of supporting and progressing Indigenous students through higher education was found. Despite this a number of domains that affect student retention were identified, they include; support from Indigenous and non-Indigenous academics; inclusive curricula; strong community engagement, access to appropriate and timely information/support, mentoring, peer support and financial assistance (Barney, 2016; Gore, Holmes, Smith, Fray, McElduff, Weaver, \& Wallington, 2017; Teevale \& Teu, 2018). Domains that were student intrinsic include resilience and social and emotional well-being (Hall, Maughan, Wilkes, Thorpe, Forrest and Harrison, 2015; Toombs, 2010).

Family and community were frequently mentioned in the literature concerning enabling programs but were scarcely mentioned in the literature concerning university. As an example, the support and understanding of family and community "was found to be crucial to students pursuing their 
aspirations, as well as during participation in higher education" (Gore, et al, 2017, p. 337) and "Students report unwavering family support as a crucial factor in pushing them forward in their studies" (Pechenkina and Anderson, 2012, p.23).

Oliver, Grote, Rochecouste, and Dann (2015) conducted interviews with 57 Indigenous students at one university and found that "...support from family members featured most prominently in the qualitative data and was often deemed to be the major factor in the students' completion" (p. 28).

Family in this context, however, was regarded as a double-edged sword with some students experiencing that change in identity as leading to a change in relationships. For some students family was described as aspirational and supportive although

Balancing familial expectations with the demands of university learning was a constant struggle.

However, the desire to persist and become strong role models for those within their families and communities saw them through some of the most challenging of life events throughout the course of their studies. (Hill, Winmar and Woods, 2018, p.9)

In the literature, the term family tended to be used in a general sense. There was rarely any distinction made between a student's family of origin (i.e. their parents) and a student's family of creation (children they may be raising) despite the fact that they produce very different sets of pressures. The Success Officers, from their lived and working experiences, indicated parental pressure may arise from fears their child will leave a community and abandon cultural responsibilities; raising children whilst attending university places financial and time constraints on students.

The link between successful first year and completion is noted in the literature and with it the need for special attention for at risk students (Teevale \& Teu, 2018). One paper from student counselling literature showed a link between outreach and counselling and retention. The Rickinson project (1998) reached out to students who were identified as being at risk of dropping out and offered counselling. Of the 43 at risk students who were contacted at end of 1st year, 15 students took up the offer of counselling and from those, 11 students progressed. Similar results were identified for final year students. Although UK based, the Rickinson paper highlighted several important points relevant for our Indigenous students. For example, Rickinson states "vulnerable and distressed students do not normally take the initiative to access the help that is available to them" (p.100). The Success Team felt this highlighted a mechanism by which the high drop-out rates of Indigenous students enrolled at Edith Cowan University over the summer breaks could be prevented.

Recent literature, Anderson, Edwards and Wolfe (2016), and Hill, Winmar and Woods (2018) indicates students have benefitted from the opportunity to see their learning journey as a transformative process. Yarning and storytelling are valued processes for highlighting the resilience that is built though transforming a challenge and not being defeated by it. Yarning and storytelling also empower the individual as they learn how others positively perceive their changes. This was also a theme in the Student Survey (2019), which indicated more students felt that being transformed by the process of gaining a degree was as important as gaining the degree.

In summary, the findings from the higher education Indigenous student success discourse indicated the Support Success Service needed to incorporate mechanisms by which Indigenous and nonIndigenous academics could be engaged to support students; students were able to maintain and forge new links with community, students could access appropriate and timely information/support, mentoring, peer support and financial assistance. The significance of financial assistance cannot be underestimated. In the Student Survey (2019) this was identified by $24 \%$ of students as the most significant barrier to success, and work responsibilities were identified as a barrier by $15 \%$ of students. The findings also indicated that family is significant and may, in some circumstances, need to be encouraged to be supportive.

The discourse concerning the efficacy of services targeted to marginalised people, and in particular, responding to people who have a variety of challenging life circumstances, was considered. 
Robertson (2015), conducted an analysis of the literature and found those services demonstrating the following are more likely to achieve effectiveness across a range of outcome measures:

- Grounded in theory (based on the best available evidence);

- Targeted and tailored to context (i.e. targeted to the university context and tailored to the student's needs);

- Operationalised and flexible (having specific processes that also allow for intangibles such as the provider/recipient relationship and the providers' experience and skills);

- Program coherence (having a mission and key values or operational principles that can be seen at all levels of the service system); and

- Produce measurable outcomes (i.e. an outcome that demonstrates a change in the recipient as a result of receiving the service).

There were three factors of note in the discourse concerning the efficacy of services targeted to marginalised people. Firstly, there were scales of intervention ranging from prevention (offered universally), responsive support (to those asking for help), out-reach support (for those at risk and not yet asking for help) and mandated intervention. Mandated intervention is used for serious situations such as mental health crisis and child protection and was not considered appropriate in this context. The Student Success framework helps to identify serious situations and to make appropriate referrals but it is not in a position to enforce interventions. Secondly, outreach service delivery is designed for what the literature termed 'hard-to-reach', defined as those who are most in need of, yet least likely, to access support. This echoes findings outlined by Rickinson (1998), who identified that at risk students were least likely to access help, benefitted significantly from out-reach efforts from service providers. Thirdly, services should be clear in their aims and parameters.

In summary, the discourse concerning the efficacy of services targeted to marginalised people gave some very valuable pointers about the mechanisms of service delivery. The Success Team decided to adapt each aspect. For example they identified:

- The service mission as getting the right support to the right student at the right time;

- The operational principles as collaboration, transparency, respectful entry into complexity, a solution oriented approach (rather than focussing on problem identification), enhancing cultural dignity; and

- That the service delivered would have ongoing usefulness for students.

Population trends were used to establish demographic profiles of Indigenous people as potential students in Western Australia. These were considered in conjunction with demographic profiles of current ECU Indigenous students derived from the annual Aboriginal Student Satisfaction Survey. The findings had a major impact on the team's understanding of various aspects of student progress and in turn influenced the type of support offered to students. For example:

Firstly, Australian Indigenous women begin having children nearly six years younger than nonindigenous women and they have more children (total fertility rates were 2.115 births per 1,000 compared with 1.789 per 1,000 women in the general population. Median age at first motherhood was 25.5 years for Indigenous women compared with 31.2 years for mothers within the total population. (AIHW, 2016). In Western Australia (WA), 60\% of Indigenous students are female and the majority of students are over 25 years. This was born out by the Student Survey (2019) where $39 \%$ of students were primary carers. Caring for children is a primary concern for parents, and university requirements will be a secondary concern. When asked 'Which barriers affect you as a student?' the second top response (20.5\%) said family responsibilities.

Secondly, in WA, $22 \%$ of Indigenous people live in regional areas, and $40 \%$ in remote and very 
remote areas (ABS, 2016). Students are more likely to travel for their university education, interrupting filial and cultural responsibilities or they may rely on online courses. This was born out by the Student Survey (2019), where 20\% had relocated, 32\% studied exclusively on-line and 16.57\% studied partially online. Relocation may lead to social isolation, homesickness and persistent guilt if filial responsibilities are left to others. The Student Survey (2019) indicated relocation was the second major reason for considering withdrawal $(21.13 \%$ ). These two factors, (being a parent and living in a regional or remote area), often co-exist, and may be a significant contributor to the fact that only $44 \%$ of students were enrolled in an academic load typical of a fulltime student. In addition, $32 \%$ of Indigenous students at ECU enrolled following a university preparation course. This means that being an enrolled student and participating in the university experience may be required for far longer than is typically needed for non-Indigenous students to graduate. This longer university journey may be a contributing factor to the drop-out rates between years. Longer completion times tend to be seen in the literature as a negative. The Success Team rather saw some extension of the university journey as positive, enabling students to enjoy cultural and parenting continuity. The team believed that specific attention to students between years one and two and between two and three may help reduce drop-out rates.

In summary the statistics concerning Western Australia Indigenous students indicates they are more likely to be older than non-Indigenous students, to be parents and/or supporting family members, attending to community and cultural responsibilities at some distance from the university. All these factors contribute to the well-being of Indigenous people as well as necessitating an extension of the university journey.

\section{The Student Success Service}

The Success Team built an operational framework, at the heart of which are two linked matrices. The First Contact Screening Matrix consists of nine domains the team identified from the literature as having the most impact on a student's capacity to study at university. These are Family of Origin, Family, Family of Creation, Employment, Finances, Coping with study, Personal and health issues, Relocation, University systems and On-line study. Each domain can be either an asset to a student or a barrier to completion and that may change at any time. Each domain therefore is described in five different phases, these are being an asset, being a limited asset, being either a potential asset or barrier, being a barrier and being such a barrier it was hard to continue at university. For example the Family of Origin domain statements are:

1. My family support me and understand the level of commitment I need for my studies;

2. My family support me but do not understand my level of commitment to my studies;

3. My family think I am better than them for wanting to attend university;

4. My family didn't enjoy school and think I shouldn't attend university; and

5. My family doubt my ability to succeed at university.

The second 'On Track' matrix is the same but couched in 'how is it now' language.

Five potential levels of support were identified. The first two, welcoming and motivational, are offered universally on starting university, this includes a welcome package and voucher. Further welcoming and motivational support includes regular newsletters about activities and information about support available. At the third level (prevention) Student Support Officers make motivational and well-being calls at multiple points in each year; during orientation and at weeks 6,9 and 12. At that call all students are offered, on an opt-in basis, a check-up using the first contact screening matrix. The matrix helps students identify their strengths and vulnerabilities. At this point, where indicated by the matrix, the student is offered access to specific supports such as scholarships and tutoring. The fourth level (responsive support) is the use of the second On Track matrix to determine if support 
provided has been effective. The fifth level (out-reach) consists of calls and the use of the On Track Matrix to students identified by academic staff or when academic records show the student is at risk of failing and/or dropping out. Both fourth and fifth levels can be described as a casework type of response in that the Success Officer establishes a relationship with the student and supports them through their difficulties, often with multiple specific supports, or helps them defer or withdraw.

When either matrix is used, and a mark made on a continuum below the first stage of any domain the conversation concerns how the student's situation can be improved. This may include targeted information such as scholarships, access to tutoring, and assistance with courses about academic writing. It may include assistance to access housing or Centrelink (social security payments), counselling, or local disability services. If the student identifies multiple barriers or has a mark in the 'hard to continue' stage a tailored response is offered, this may include referrals to services and a sequence of supportive contacts. At follow-up the On Track matrix is used to see if the student has changed their position on the matrix.

The matrices are used in accordance with following operational values:

- Collaborative. The Success Officer and student sit together (or converse on the phone) with the matrix on the table (or on the computer screen) in front of them, looking at the matrix rather than each other. Together, through a process of yarning, they construct a meaningful picture of the student's context, barriers and enablers;

- Transparency. The matrix is the record, thus recording occurs in front of and with the consent of the student. The matrix, and the way it is applied, enables the student to locate where they are now within a range of possibilities and to know that their response is recorded accurately. The student and the Success Officer keep a copy of the completed matrix as it is used in any follow-up calls;

- Respectful entry into complexity. The use of matrix encourages a conversation that supports students to focus their thoughts and feelings about who they are and about their university journey with progressive entry into the personal and relationship sphere. The use of statements means the student does not have to unpack their issues as this is not a counselling session. Rather they can identify issues and accept information and/or a referral to a specialised service;

- Cultural dignity. The matrix, when delivered by Indigenous Success Officers, accepts the exigencies of the Australian Aboriginal family system and student's commitments to community and cultural responsibilities; and

- Ongoing usefulness for participants. The process of doing the matrix identifies potential barriers before they become a problem and offers early intervention. This can have ripple effect on enhancing family functioning and building social capital.

\section{Supporting Success Officers}

Toombs (2010) identified that there was no formal training for Indigenous support staff in how to support Indigenous students and in many instances student support staff were not adequately trained to deal with the issues presented to them. Also there was little indication of staff accessing support for themselves as a result of student problems. Toombs (2010) advocated training should include counselling training/skills, an established debriefing process for staff and mental health first aid training.

Student Success Officers considered ways in which they could be supported. This included receiving mental health first aid training and developing a debriefing process. As they were not counsellors it was felt that the matrix tended to delay the unpacking of serious issues until the student was with an appropriately trained specialist. Success Officers built a resource directory so that referrals could be 
made. Success Officers divided their time between campuses and developed specialist skills. For example one Success Officer conducted calls for students studying exclusively on-line.

\section{Generating a feedback loop}

The framework generates quantitative data from the matrices. Each domain, each level on each continuum and each support type is numbered. Numbers are collected on a spreadsheet and can be aggregated. Completed matrices have a mark in a number of domains (not all domains apply to all students), this tells us what domains affect students. Each marked domain has a mark somewhere along the continuum, this tells us how domains affect students. Some continuum have a before and after support mark which tells us whether the support provided was efficacious.

Students are invited to use the matrix and may opt out without it affecting their relationship with the Success Team. When they first use the matrix, and if a second application is completed, students are invited to give feedback on the process of support. This is in the form of a questionnaire or an interview depending on the choice made by the student and asks:

- In what way were you assisted by the Student Service?

- What was helpful and why?

- What was unhelpful and why?

- What would you like to see improved?

This qualitative data is aggregated using thematic analysis. Additionally Success Officers are interviewed at the end of each semester, also providing qualitative data. At the end of each semester all the data are collated in a report where recommendations about changes to any aspect of the service can be made.

\section{Findings from the experimental phase.}

In the experimental phase, the matrix was used with 21 students, of whom 17 students were newly enrolled and 4 students had either called for help or had been the subject of an outreach call. Not all domains applied to all students. Of the 21 students completing a matrix, all used the Family of Origin (FoO), Finances, Personal and Health issues and University Systems domains. Twelve (12) used the Family of Creation domain indicating nearly $57 \%$ of students are parents. Employment was marked by 12 students indicating 52\% were also working. Relocation was marked by 5 students indicating $24 \%$ had relocated to attend university and $57 \%(\mathrm{~N}=12)$ were engaged in on-line courses at some level. 


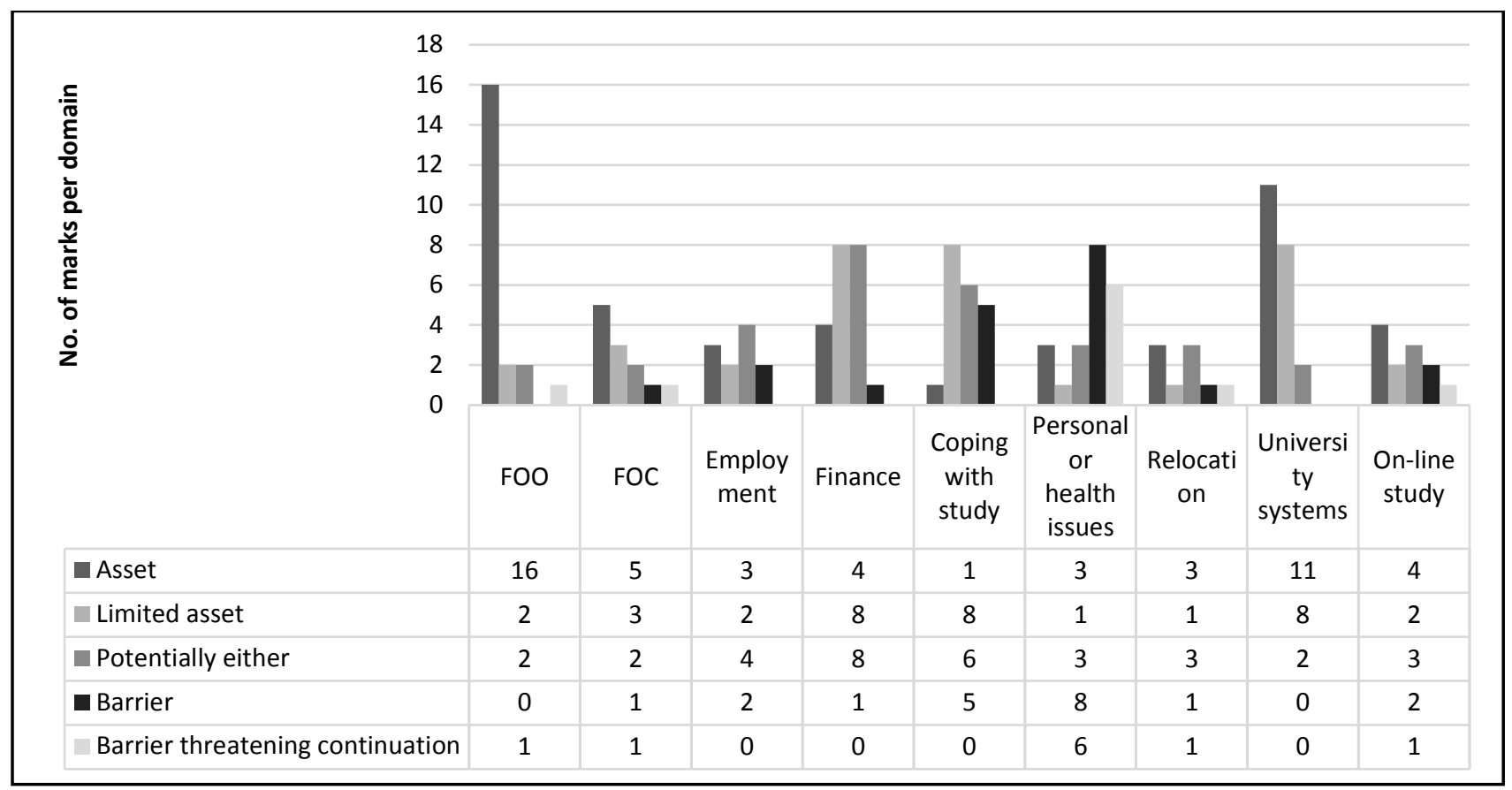

Fig. 1 Aggregated matrix data

\section{Outcomes for students}

Of the 148 marks made on the matrix $24 \%(\mathrm{~N}=85)$ were positive, that is, in asset or limited asset stages of the continuum. Twenty-two $(22) \%(\mathrm{~N}=33)$ marked the stage where the domain could potentially be either an asset or a barrier and $20 \%(\mathrm{~N}=30)$ marked the stage where the domain was a barrier or a barrier that could threaten continuation.

Success Officers offered specific supports with students who marked any domain at the third, fourth or fifth stages on the continuum. Some newly enrolled students did not want any intervention at that time, as they wanted to see how things went. Some wanted and received targeted supports including scholarships, mentoring and tutors; follow-up revealed these supports had been used with successful outcomes. Nine (9) students received a tailored intervention which included any of the aforementioned, also a specific support that targeted, for example, disability or mental health issues and ongoing support (a sequence of encouraging calls and/or meetings with a Success Officer). This enabled at risk students to continue their university journey. Four students, who were considered at risk of dropping out were supported to temporarily discontinue study. This ensured they left university with good standing, paving the way for a resumption of studies.

As can be seen from the graph the greatest support for students is their family of origin, however, for the five for whom family of origin was not supportive, the outcome was catastrophic and was the reason cited for two discontinuations. University systems were noted as being a major support for students. Finances were a concern but not a reason for discontinuing study. Likewise coping with study was a concern for 10 students but not a reason for discontinuing study. The greatest challenge for students was personal and health issues and was the cause of two discontinuations.

\section{Discussion}

The experimentation phase enabled the team to make a number of refinements. The earliest refinements concerned the use of statements in each continuum rather than a numerical scale. From the student perspective the difference is significant. For example, using a scaling question on the Finance domain would mean the student hears: 'On a scale of 1-5 where one means "no problem" and 5 means "it threatens my progress through university" where would you rate your finances?' When posed questions such as these students tend to think out loud and try to work out where they 
are now and where they might be depending on variables such as gaining or losing employment. The Success Officers found such numeric scaling question tend to lead to a long, problem-focused, content-driven discussion.

Using statements such as the following leads to a shorter, solution-focused, process-driven discussion, for example. 'Regarding your finances which statement is most accurate for you right now?

- I am financially stable and have an income for the duration of my degree.

- I have a relatively stable income, and scholarships will help me get by.

- My income is low, it'll be fine once I graduate and go into the workforce.

- It's going to be hard to balance finances and work life. I struggle to make ends meet.

- I'm worried I won't be able to complete my university degree.

From the perspective of data collection, all the above statements provided a better fit with the fivestage continuum giving greater accuracy and understanding.

Once the Success Officers felt confident about the introductory language of the matrix and the accuracy of the statements they made the matrices available to all Indigenous students to use as well as applying them in the previously described contexts.

One of the Success Officers constructed an on-line version with an 'opt-in' option so that data could be collected from any use of the matrix. This on-line version is also used to support students studying via on-line courses.

The use of the matrix helped to identity the context of each student user and facilitated the development of specific supports matched to the student's needs and context. For example it was realised there are few supports for families of origin or creation. In particular supports that challenge attitudinal resistance to the student attending university were not readily available.

The Success Team explored whether other universities had responded to this need. Of particular merit was Otago University, New Zealand, which, through its Indigenous Centre it produced the 'Whanau Guide', specifically for families of students. The Success Team at Edith Cowan University began to write their own family guide booklet, and organised family days. The Success Team also began a small research project to access families and ask what would help them to help their student.

Aggregated matrix data and previously mentioned research indicates that finances are often a problem for students. Scholarships require a lengthy application process and applications are not always successful. The Success Team established a Best Start Scholarship to be awarded to Indigenous students through allocation rather than application. The allocation process is based on a point system that includes a number of factors including socio-economic status, area of study and specific hardships. Students who are allocated more than 80 points are awarded a Best Start scholarship on a pro-rata basis, with each unit enrolled realising $\$ 250$ with a maximum of $\$ 1000$ per student. This scholarship, and the innovative mechanism for distribution, has paved the way for a more streamlined process and reduces the burden on students. Through this process 63 scholarships were awarded in 2019.

Aggregated matrix data indicated Personal and health issues, that typically included mental health problems and disabilities, can to be a barrier to retention. In two (2) uses of the matrix during the experimental phase the student identified that because of personal and health issues it was not the right time for them to be studying. The use of the matrix gave them the opportunity to come to a decision to defer enrolment. Five (5) other students were able to continue after being connected to appropriate local services. 
Students for whom relocation was barrier were encouraged to join the regular student lunches and to use designated Indigenous students study rooms. They were also encouraged to meet the Elder in Residence at their campus and to make connections with Indigenous people and groups in the local community.

Success Officers began developing their own support system, including the development of a manual, a training calendar and a resource toolbox. At the beginning of 2020 the Success Team prepared to use the matrix with the hundreds of new Indigenous students.

\section{Conclusion}

The inclusive, reflexive and emancipatory nature of collaborative, co-operative and action research methodologies were ideally suited to the capacity building needs of Kurongkurl Katitjin and the professional development of the Success Officers at an Australian university. The framework they developed provides an ongoing feedback system to respond to changes in student needs over time. The framework is used to support Success Officers, to collaborate with students, and to identify the students' strengths and vulnerabilities at specific times in their university career. In response to the use of this innovative student success system a variety of supports and interventions may be provided. There will be ongoing exploration of the efficacy of this intervention. The framework generates quantitative data supplemented with qualitative data generated by interviews with a number of service recipients and Success Officers. At the end of each semester data is aggregated, this informs the Student Success Service of the relevance of the elements of the framework and the appropriateness of inputs.

The outcomes for students so far are entirely positive. Used at the beginning of their university journey they are helped to identify their strengths and potential vulnerabilities. At this point they may opt for support or wait until they need it, knowing what help is available. Perhaps the greatest benefit is for 'at risk' students who, despite scoring very low on multiple domains are able to accept support, continue studying and enhance their relational, family, cultural, academic and personal identity adjustment as impacted by their enrolment in higher education. Alternatively if the timing and personal situations are not a good fit the students are helped to discontinue or defer enrolment on a temporary basis.

The generation of data in the use of framework in this context can be described as a quality assurance mechanism, however, as predicted early in its development, it has also identified needs for further research. For example, it confirmed an identified lack of appropriate supports for students with barriers associated with both family of origin and family of creation. Gaining ethics approval early in the development of the system allowed for requests for consent for follow-up interviews with students and their families to be made. The Success Team has embarked upon a research project in which the families of students will be accessed to explore how they can be supported to transition from being a barrier to an asset. This will involve in depth interviews with families. Ethics approval enabled this paper to be submitted for publication and will enable further publications that presents data generated by the more widespread application of the framework. 


\section{References}

Australian Bureau of Statistics (2016). - Census of population and housing: Aboriginal and Torres Strait Islander Peoples profile datapack, $\quad$ Australia, 2016. 2069.0.30.002. $\quad$ Retrieved from https://www.abs.gov.au/ausstats/abs@.nsf/0/879B62283A7DEABBCA25734100166B54?

Australian Institute of Health and Welfare (2016). Australia's health 2016. Retrieved from https://www.aihw.gov.au/getmedia/9844cefb-7745-4dd8-9ee2-f4d1c3d6a727/19787-

AH16.pdf.aspx?inline $=$ true

Anderson, C., Edwards, A. \& Wolfe, B. (2016). Finding space and place: Using narrative and imagery to support successful outcomes for Aboriginal and Torres Strait Islander people in enabling programs The Australian Journal of Indigenous Education, (46)1, 1-11. doi 10.1017/jie.2016.11

Australian Government Department of Education (2019). Higher education student collection, 2019. Retrieved from https://www.education.gov.au/higher-education-statistics

Barney, K. (2016). Listening to and learning from the experiences of Aboriginal and Torres Strait Islander students to facilitate success. Student Success, 7(1), 1-11. doi:10.5204/ssj.v7i1.317

Delahunty, J. \& O'Shea, S. (2019). I'm happy, and I'm passing. That's all that matters: Exploring discourses of university academic success through linguistic analysis. Language and Education, (33)4, 302-321, doi: $10.1080 / 09500782.2018 .1562468$

Fahy, K. (2009). Quality improvement research: Can it be published? Women and Birth, 22(1), 1-2. doi:10.1016/j.wombi.2009.01.002

Gore, J., Holmes, K., Smith, M., Fray, L., McElduff, P., Weaver, N. \& Wallington, C. (2017). Unpacking the career aspirations of Australian school students: Towards an evidence base for university equity initiatives in schools. Higher Education Research \& Development, (36)7, 1383-1400. doi: 10.1080/07294360.2017.1325847

Hall, L., Maughan, C., Wilkes, M., Thorpe, T., Forrest, J. and Harrison, (2015). Swimming not drowning - resilience as a key determinant of success for Aboriginal and Torres Strait Islander pre-tertiary students. Journal for Multicultural Education, (9)3, 159-173. Retrieved from https://doi.org/10.1108/JME-12-2014-0045

Heron, J. (1996). Co-operative inquiry: Research into the human condition. Thousand Oaks, CA: Sage,

Hill, B., Winmar, G., \& Woods, J. (2018). Exploring transformative learning at the cultural interface insights from successful Aboriginal university students. Australian Journal of Indigenous Education, 1-12. doi10.1017/jie.2018.11

McNiff, J. (2013), Action Research. Retrieved from www.proquest.com/products- services/ebooks-main.html

National Health and Medical Research Council (2014). Annual report 2013-2014. Canberra: National Health and Medical Research Council. Retrieved from https://www.nhmrc.gov.au/sites/default/files/2018-02/NHMRC-Annualreport-2013-14.pdf

Office of Māori Development, (Undated). Whanau guide. New Zealand: University of Otago.

Oliver, R., Grote, E., Rochecouste, J., \& Dann, T. (2015). Indigenous student perspectives on support and impediments at university. The Australian Journal of Indigenous Education, 45, 23-35. doi:10.1017/ jie.2015.16.

O'Shea, S \& Delahunty, J. (2018). Getting through the day and still having a smile on my face! How do students define success in the university learning environment? Higher Education Research \& Development, 37:5, 1062-1075, DOI: $10.1080 / 07294360.2018 .1463973$

Pechenkina, E. and Anderson, I. (2011). Background paper on indigenous Australian higher education: Trends, initiatives and policy implications. Paper presented at The Review of Higher Education Access and Outcomes for Aboriginal and Torres Strait Islander People, Commonwealth of Australia.

Reason, P. \& Rowan, J. (1981), Human inquiry, a source book of new paradigm research. New York: John Wiley and Sons, Ltd.

Rickinson, B. The relationship between undergraduate student counselling and successful degree completion, 1998. Studies in Higher Education, (23)1.

Robertson, F. (2012) An exploration of the effect of a tobacco-related harm reduction strategy on parents in the hardto-reach population. Thesis (Ph.D.) University of Western Australia, 2012.

Teevale, T. \& Teu, A. (2018). What enabled and disabled first-year Pacific student achievement at university? Journal of the Australian and New Zealand Student Services Association, 26(1), 15-27. doi:10.30688/janzssa.2018.04. 
Toombs, M. (2010). Recommendations from research into what Aboriginal students say affects their social and emotional wellbeing while at university. Aboriginal and Islander Health Worker Journal, (34)6, 22-24. Retrieved from https://search-informit-com-au.ezproxy.ecu.edu.au/documentSummary;dn= 605367584821680;res=IELIND

Universities Australia, (2017). Universities Australia, Indigenous strategy 2017-2020. Retrieved from https://www.universitiesaustralia.edu.au/wp-content/uploads/2019/06/Indigenous-Strategy-v16-1.pdf

Universities Australia, (2017). Universities Australia Indigenous strategy 2017-2020 first annual report https://www.universitiesaustralia.edu.au/wp-content/uploads/2019/06/20190304-Final-Indigenous-StrategyReport-v2-2.pdf

The authors may be contacted via

f.roberston@ecu.edu.au

\section{Please cite this paper as:}

Hill B., Robertson, F., Winmar, Lee, T., Casey, T., Lindsay K., G. \& Bennell, D., (2020). The development of an evidence based, evidence generating framework for enhancing Indigenous student success at an Australian university. Journal of the Australian and New Zealand Student Services Association, 28(1), 21-33.

https://doi.org.10.30688/janzssa.2020.03 